Çukurova Üniversitesi Mühendislik Mimarlık Fakültesi Dergisi, 32(3), ss. 69-80, Eylül 2017

Çukurova University Journal of the Faculty of Engineering and Architecture, 32(3), pp. 69-80, September 2017

\title{
Kent Geometrisine Bağlı Olarak Kentsel Isı Adası Etkisinin Belirlenmesi: Konya Örneği
}

\author{
Fatih CANAN $^{* 1}$ \\ ${ }^{I}$ Selçuk Üniversitesi, Mimarlık Fakültesi, Mimarlı Bölümü, Konya
}

Geliş tarihi: 08.06 .2017

Kabul tarihi: 25.09.2017

$\ddot{\mathbf{O} z}$

Kentsel 1Sı adası etkisi, kentlerin yapısal yoğunluklarının artması sonucu gözlemlenen olumsuz bir mikroklimatik koşuldur. Çalışmada Konya kenti bağlamında seçilen 4 bölgede, kentsel dokuların geometrik oluşumuna bağlı olarak maksimum kentsel isı adası etkileri belirlenmiştir. Elde edilen sonuçlar dikkate alındığında, maksimum 1sı adası etkisinin, gökyüzü açıklıkların düşük olduğu yoğun kentsel alanlarda yüksek değerlerde olabileceği belirlenmiştir. Gökyüzü açıklık değerleriyle 1s1 adası etkisi arasında ters orantı söz konusudur. Konya kenti için az yoğun yerleşim alanlarının (yüksek SVF değerleri) planlanması daha uygun bir yaklaşım olabileceği sonucuna varılmıştır. Bu durumda, yaz dönemlerinde kent ortamında gece oluşan 1sı adası etkisinin azaltılmasının ve kışın da binaların az yoğun yapılaşmaya bağlı olarak güneşten pasif olarak yararlanabilmelerinin mümkün olabileceği belirtilmiştir. Son olarak ülkemiz koşullarında planlama ve tasarım aşamalarında yapılaşma yoğunlukları belirlenirken SVF parametresinin bir girdi olarak değerlendirilmesinin gerekliliğine vurgu yapılmıştır.

Anahtar Kelimeler: Kentsel ısı adası, Kent geometrisi, Gökyüzü açıklı̆̆ı, Kentsel planlama, Mimari tasarım

\section{Determination of the Urban Heat Island Effect Related to Urban Geometry the Example of Konya}

\begin{abstract}
Urban heat island effect is a negative microclimatic condition observed as a result of the increasing of the cities density. In this study, the maximum urban heat island effects were determined according to the geometric formation of urban fabric of 4 areas selected in the context of Konya city. According to the obtained results, it was determined that maximum urban heat island effect has high intensity in dense urban areas where the sky opening values are low. There is an inverse relationship between sky opening values and heat island effect. It was concluded that planning urban areas with low density (high SVF values) for Konya city would be a more appropriate approach. In this case, it may be possible to reduce nocturnal heat island effect during the summer period in urban environment and the possibility for buildings to benefit from the sun in a passive way due to the less construction density. Finally, emphasis was made on the evaluation necessity of SVF parameter as a input in determination of construction densities in the planning and design phases in our country conditions.
\end{abstract}

Keywords: Urban heat island, Urban geometry, Sky opening, Urban planning, Architectural design

"Sorumlu yazar (Corresponding author): Fatih CANAN,fcanan@selcuk.edu.tr 


\section{GíRISş}

Dünya genelinde kentlerde yaşayan insanların sayısında büyük artışlar gözlemlenmektedir. Dünya sağlık örgütü verilerine göre, 1960 yılında dünya toplam nüfusunun \%34'ünü, 2014 yılında ise \%54'ünü kentli nüfus oluşturmaktaydı. Bu oranların önümüzdeki yıllarda, çoğunlukla gelişmekte olan ülkelerde artarak devam edeceği tahmin edilmektedir. Günümüz kentlerindeki bu nüfus artışı, ekonomik, sosyal ve çevresel sorunları da beraberinde getirmektedir. Bu bağlamda büyük kentlerde sıklıkla görülen olumsuz mikroklimatik koşullar önemli bir çevresel sorun olarak karşımıza çıkmaktadır. Kentte insan aktivitelerinin artması, kent dokusunun morfolojik yapısının değişmesi ve bitkisel yüzeylerin azalıp sert yüzeylerin artması, olumsuz mikroklimatik koşulların oluşumuna zemin hazırlamaktadır. Büyük kentlerde görülen mikroklimatik problemlerin başında kentsel 1S1 adas1 etkisi gelmektedir. Kentsel 1s1 adas1, yerleşim yerlerinin çevrelerinde yer alan kırsal bölgelere göre daha yüksek hava sicaklık değerlerine sahip olması durumudur [1,2]. Kentsel 1s1 adas1; kent hava kalitesinin düşmesine, binaların soğutulması için enerji tüketimlerinin artmasına, klima sistemlerinin yoğun kullanımına bağlı elektrik dağıtım şebekelerinde arızaların meydana gelmesine, kent üst tabakasında kirliliğe, rüzgar, nem ve yağış rejimlerinde değişmelere neden olmaktadır [3]. Diğer taraftan risk grubu taşıyan hastalarda ve yaşlı insanlarda, sıcak hava dalgalarının yaşandığ 1 günlerde ciddi sağlık sorunlarına ve ölümlere de neden olabilmektedir [4].

Kentin geometrik yapısı, kentsel 1sı adası etkisinin oluşumunu etkilemektedir [5-7]. Oke'ye [8] göre bu oluşum çoğunlukla gece meydana gelmektedir. Kış aylarında olumlu olabilirken yaz dönemlerinde istenmeyen sıcaklık artışlarına neden olmaktadır $[8,9]$.

Günümüzde sürdürülebilir kalkınma bağlamında kent formuyla iklim arasındaki ilişkilerin belirlenmesi önemli bir araştırma alanı olmuştur [10]. Kent iklimi üzerine dünya genelinde son 30 yılda yapılan bilimsel çalışmalara rağmen, ülkemiz kentlerinde gerçekleşen ve devam eden kapsamlı kentsel yenileme ve dönüşüm uygulamalarında, mikroklimatik araştırmalara yeterince yer verilmediği görülmektedir. Gelişimleri ve dönüşümleri hızla devam eden kentlerimizde, mikroklimatik koşulların ne durumda olduğunun belirlenmesi ve ona göre planlama ve tasarım stratejilerinin geliştirilmesi sürdürülebilir bir gelecek için büyük önem taşımaktadır.

Kent dokusunun geometrik yapısına bağlı olarak oluşması muhtemel maksimum kentsel 1s1 adas1 etkisinin gökyüzü açıklık değerlerine göre bir ön araştırma kapsamında belirlenmesi mümkündür. Çalışma bu çerçevede gerçekleştirilmiştir. Ülkemizin büyük kentlerinden olan Konya'da belirlenen 4 farklı özellikteki kentsel dokuda, gökyüzü açıklık değerlerinin analizleri yapılmış ve harita üzerinde dağılımları gösterilmiştir. Seçilen bölgelerdeki gökyüzü açıklıklarının ortalamalarına bağlı olarak oluşabilecek maksimum kentsel 1s1 adası değerlerinin belirlenmesi amaçlanmıştır. Çalışmamız kapsamında kentin biçimsel yapısı bina gruplarının ve bunların oluşturduğu açık alanların birlikteliğinden meydana gelen hacimsel oluşumlar olarak basite indirgenerek ele alınmıştır [11].

Kentsel 1S1 adasının oluşumunda kontrol edilemeyen ve edilebilen değişkenler söz konusudur [12]. Rüzgar hız1, bulutluluk oranı, antisiklon koşulları, doğal kökenli olup kontrol edilemeyen değişkenlerdir. Kentin biçimsel ve geometrik yapıs1, bitkisel unsur ve yüzey kaplama malzemeleri gibi değişkenler ise planlamacılar ve mimarlar tarafından kontrol edilebilirler. Temel bir belirleyici olan ve yapılı çevrenin oluşumunda kalıcı etkisi olan kentin biçimsel ve geometrik yapısı, bu çalışmada odaklanan temel konu olmuştur.

\section{KENT ORTAMINDA İKLİM}

Kentler bulundukları doğal ortamı değişikliğe uğratarak yeni çevresel koşullar meydana getirirler. İnsanlar tarafından üretilmiş kendine özgü ekolojik ve atmosferik koşulları içlerinde barındırırlar [13]. Kentlerin morfolojik özellikleri iklimsel değişiklikler üzerinde çok yönlü karmaşık etkileri bulunmaktadır [14]. Kent formunun kent 
mikrokliması üzerinde belirgin bir etkisinin olduğu çok sayıdaki araştırmada gösterilmiştir. $\mathrm{Bu}$ araştırmalar özellikle kent içindeki sıcaklıkların dağılımları ve hava akımları ile ilgilidir [15].

Kent ortamında mikroklima ölçeğinde yapılan araştırmalar yükseklik bakımından birkaç yüz metre ile sinırlıdır [10]. Bu ölçekte insan müdahaleleri ve dolayısıyla kent formu iklim üzerine etki yapabilmektedir. Kent formuyla iklim arasındaki etkileşim atmosferde farklı ölçeklerde üst üste gelen hava katmanlarında meydana gelmektedir. $\mathrm{Bu}$ katmanlar farklı termik dağılımlara sahiptir. $\mathrm{Bu}$ katmanlar arasında, kentsel kanopi katmanı zemin seviyesine en yakın olanı olup mikroklimatik ölçektedir [16]. Bu çalışma kapsamında da dikkate alınan katmandır. Kent zemini (sokaklar, açık alanlar) yapı hacimleri ve yeşil alanlar bu katmanda değerlendirilir.

Kentin geometrik yapısının, kentsel kanopi katmanının mikroklimatik karakteri üzerine etkisinin olduğu Oke [8] tarafindan yapılan çalışmalarda gösterilmiştir. Ancak şu belirtilmelidir ki, kent formunun karmaşık geometrik yapısı ve malzeme bileşenleri, kent düzeyinde mikroklimatik etkilerin gerçekçi bir şekilde belirlenmesini güçleştirmektedir. Kent formunun yerel ölçekte iklim üzerine olan etkileri çok kesin bir şekilde belirlenmesi oldukça güçtür [16].

\subsection{Kent Geometrisi ve Isı Adası Etkisi}

Kentsel 1sı adası etkisi, yerleşim yerlerinin yakın çevrelerinde yer alan kırsal bölgelere göre daha yüksek sıcaklık değerlerine sahip olmaları durumudur (yüzeylerde ve hava ortamında) [17]. Gün boyunca sabit bir değere sahip olmayıp, zamana bağlı olarak değişkenlik göstermektedir [18]. Kent içindeki dağılımı da eşit düzeyde olmamaktadır. Kentsel 1S1 adasının şiddeti gün batımından itibaren başlayarak yüksek değerlere ulaşmaktadır. Gece saatlerindeki etkisi gündüz saatlerine göre daha yüksek olmaktadır [19]. Kentsel 1s1 adasının şiddeti; yapısal yoğunluğa, sert zeminli yüzeylerin ve yeşil dokunun dağılımına, yüzey malzemelerinin termofiziksel özelliklerine, antropojenik 1S1 üretimine ve kentin geometrik özelliğine bağlı olarak değişkenlik göstermektedir [20]. Bu değişkenlerden kentin geometrik yapısı, kent ortamının atmosferle olan etkileşimini belirlemede öncü bir role sahiptir. Kent geometrisi, güneşten ve atmosferden bina ve diğer kent yüzeylerine ulaşan kısa dalga boylu güneş 1şımalarının ve bu yüzeylerden atmosfere doğru giden uzun dalga boylu 1şımalarının (kızıl ötesi) yoğunluk miktarını belirlemede etkilidir. Rüzgârın hızını ve karmaşık kent yüzeylerindeki enerji emilim düzeyini de kentin geometrisi belirlemektedir. Uzun dalga boylu 1şımaların uzaklaşabilmesi ve dolayısıyla isı kayıplarının oluşabilmesi, kent ortamındaki boşlukların yeterli düzeyde olmasına bağlıdır. Özellikle yaz dönemlerinde gece saatlerinde soğutma süreçleri, bina aralıklarından atmosfere doğru kaçabilen uzun dalga boylu 1şımaların yoğunluğu ile ilişkilidir [21]. Yoğun kentsel ortamlarda, birbirine yakın binalar kendi aralarında gökyüzü açıklığını belli miktarlarda engelledikleri için gündüz saatlerinde depoladıkları 1sıy1, gece saatlerinde atmosfere yaymaları zorlaşmaktadır [22]. Çünkü çoğunlukla binalardan ve çeşitli yüzeylerden atmosfere doğru kaçmak isteyen uzun dalga boylu 1şımalar (kızılötesi) yoğun doku içinde hapsolmakta, böyle olunca kent yüzeylerinde gece soğuması azalmaktadır [23]. Depolanmış 1sının uzaklaşamaması sonucunda da kentsel 1s1 adas1 etkisi meydana gelmektedir. Bu fenomen özellikle kentsel kanyon niteliği taşıyan cadde ve sokakların bulunduğu bölgelerde daha fazla gözlemlenmektedir [9]. Sözü edilen kentsel kanyon ifadesi, yüksek binaların ve dar sokakların birlikte meydana getirdikleri kentsel boşlukları belirtmektedir.

\subsection{Gökyüzünü Görme Faktörü/Gökyüzü Açıklığı}

Gökyüzünü görme faktörü (İngilizce literatürde Sky View Factor; SVF) veya gökyüzü açıklığı, kentsel iklim çalışmalarında kullanılan önemli bir geometrik parametredir. Özellikle çalışma konumuz olan kentsel is1 adası etkisinin oluşumunda kentsel geometrinin rolünü ortaya çıkarmaktadır. Gökyüzü açıklığı (SVF), boyutsuz 
bir değişken olup, kent ortamında bir noktadan gökyüzünün görüldüğü katı açıdır [11]. Kent ortamında sokak veya herhangi bir dış mekan yüzeyinde bulunan bir noktanın SVF değeri, o noktadan, yakın çevrenin meydana getirdiği engellere bağlı olarak, gökyüzünün görülme oranıdır. Daha sade bir ifadeyle, kent ortamında bir noktadan gökyüzünün görülebilirliğidir.

SVF değeri yaygın olarak 4 yöntemle belirlenir. Bunlar; analitik yöntemler, fotografik yöntemler (Fish eye fotoğraflar yardımı ile) (Şekil 1), küresel konumlama sistemi (GPS) yöntemleri ve bilgisayar yazılım yöntemleridir [14,24]. Çalışmada da kullanılan bilgisayar yazılımı yöntemi ile üç boyutlu dijital kent modellerinden SVF değerleri belirlenebilmektedir. Üç boyutlu kent modellerinde bir noktanın SVF değeri, yarımküre üzerine gerçekleşen projeksiyonlar yardımıyla hesaplanmaktadır (Şekil 2).

SVF, 0 ile 1 arasından bir değer olup bir yüzde oranını belirtmektedir [25,26]. Bir noktanın SVF değerinin bir sayısına denk olması, gökyüzünün tamamen engelsiz, yani açık olduğu anlamı çıkar. Sıfır olması ise tamamen engellenmiş bir gökyüzünün varlığı söz konusu olmaktadır [26]. SVF değerinin bire yakın olması gökyüzünde çok az engelin olduğu anlamına gelir. Bu durumda o noktadaki hava sıcaklığının açık alanda yer alan meteoroloji istasyonunun değerlerine yakın olması beklenir. SVF Sifir değerine yakın olması ortamın çok kapalı olduğunu gösterir. $\mathrm{Bu}$ durumda ise ortamın hava sıcaklığı yakın çevre koşullarından etkileneceği için meteoroloji istasyonu değerlerinden önemli ölçüde farklılaşır [10].
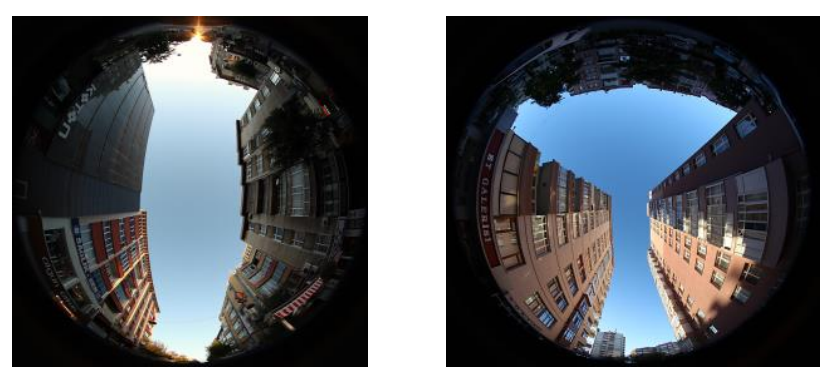

Şekil 1. Gökyüzü açıklığının (SVF’nin) tespiti için kullanılabilecek "Fish eye” fotoğraflar, Konya kent merkezi, 2017
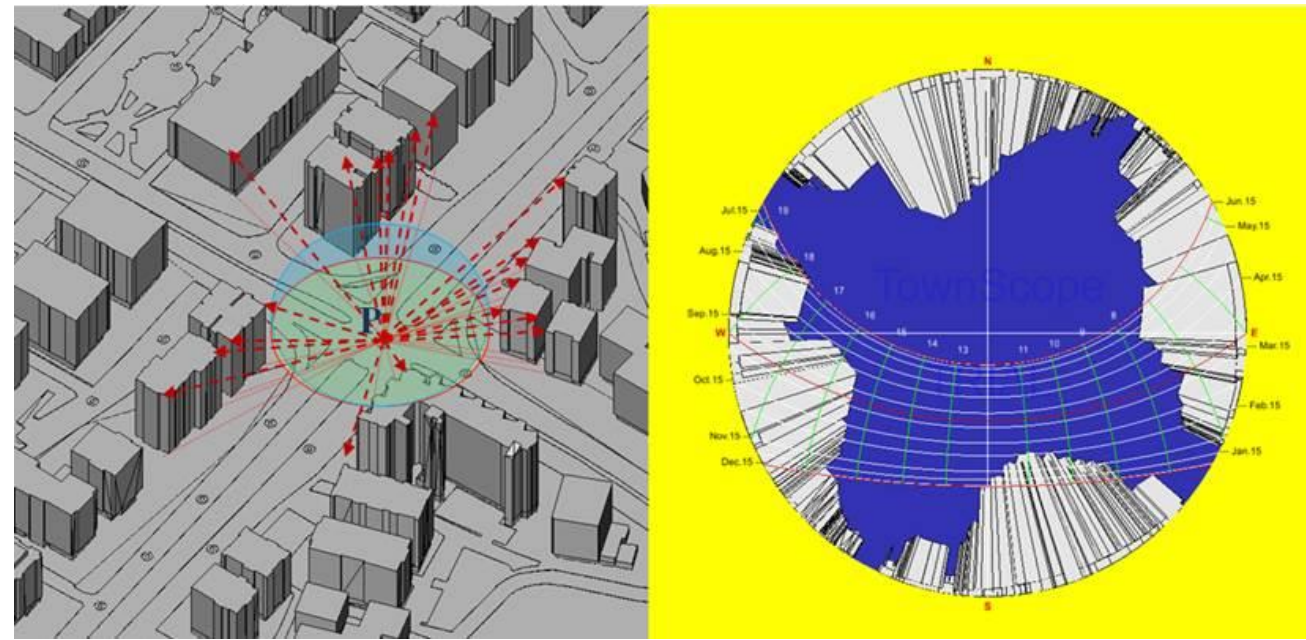

Şekil 2. Üç boyutlu kent modelinde gökyüzü açıklığının (SVF’nin) belirlenmesi (Townscope III yazılımı ile hesaplanan P noktasının SVF değeri \%68,60’dır) 


\subsection{Kentsel Isı Adası Oluşumunun Gökyüzü Açıklığına Bağlı Olarak Açıklanması}

SVF, kent iklimi üzerinde etkili olan bir parametredir [27-29]. Kentsel 1S1 adas1 etkisinin belirlendiği çalışmalarda, SVF parametresi yaygın bir kullanıma sahiptir [30-32]. SVF kentin geometrik yapısının bir temsil değeri olup, kent ile atmosfer arasındaki ışıma alışverişlerinin belirlenmesinde dikkate alınmaktadır [33]. Bir kent dokusunun termal ortami; gelen kısa dalga boylu güneş 1şımalarının ve yüzeylerden atmosfere doğru uzaklaşan uzun dalga boylu 1şımaların yoğunluğuna bağlıdır. Bu iki temel fiziksel olay doğrudan gökyüzü açıklığına, yani SVF değerlerine bağlıdır [34]. SVF değerlerinin düşük olduğu dar sokak ve yüksek yapılardan oluşan kentsel dokularda, gökyüzü açıklığı azaldığı için, kırsal yerleşimlere göre uzun dalga boylu 1şımaların uzaklaşması kısıtlı hale gelmekte, dolayısıyla kentsel isı adası etkisi de artmaktadır [22]. Geniş bir kentsel alanda, gökyüzü açıklığı ve maksimum kentsel 1sı adası şiddeti arasında bir korelasyonun varlığı Oke [36] tarafindan tespit edilmiştir. Uygun gece koşullarında, yani sakin bir havada ve bulutsuz bir gökyüzünde, maksimum kentsel 1s1 adası şiddeti $\left(\Delta \mathrm{T}_{\mathrm{u}-\mathrm{r}(\max )}\right)$, geniş bir kentsel alanda ortalama SVF $(\Psi)$ değerlerinin bir fonksiyonudur. $\Delta \mathrm{T}_{\mathrm{u}-\mathrm{r}(\max )}$ değeri, kent içinde maksimum hava sicaklığı (pik değer) ile kırsal alandaki hava sıcaklığg arasındaki farktır [35]. Maksimum kentsel isı adasının şiddeti kentin geometrik yapısına bağlık olarak aşağıda belirtilen formülle tahmini olarak hesaplanabilmektedir [36].

$\Delta \mathrm{T}_{\mathrm{u}-\mathrm{r}(\max )}=15,27-13,88 \psi$

Oke [8] tarafından geliştirilen formülün geçerliliği gece saatlerinde, antropojenik ısı salınımının yavaş seyrettiği yaz aylarında birçok Avrupa, Avustralya ve Kuzey Amerika kentinde gösterilmiştir. Bu şekilde kentsel 1sı adası etkisi kentin morfolojik yapısına bağlı olarak belirlenmektedir [37].

\section{METODOLOJí}

Konya kent merkezini temsil edebilecek nitelikte üç farklı bölge ve bir tane de yeni planlama/tasarım anlayışlarını temsil edebilecek kentin kuzey gelişme aksında yer alan bir bölge belirlenmiştir. Yapısal yoğunluk, gelişme dönemi ve kent içindeki konum bölgelerin seçimlerinde dikkate alınan kriterler olmuştur. Şekil 3'de Konya kenti genelinde analizleri gerçekleştirilmiş bölgelerin konumları görülmektedir. 1. bölge geleneksel kent merkezini temsil etmektedir. Daha çok ticaret fonksiyonları ve bazı resmi kurum binaları yer almakta olup az katlı bir yapılaşmaya sahiptir: çoğunlukla zemin dahil 2 katlı binalar mevcuttur. 2. bölge, Abdülaziz ve Beyhekim mahallelerinin bir bölümünün yer aldığ1 günümüzün modern kent merkezidir. Bu bölgede çoğunlukla zemin dahil 4,5 ve 6 katlı, ticaret, iş merkezi ve konut binaları yer almaktadır. 3 . bölge kent içinde yüksek yoğunluklu yapılaşmaya sahip Nişantaşı mahallesini kapsamaktadır. Bu mahallede zemin dahil çoğunlukla 9-10 kattan oluşan ticaret, iş merkezi ve konut binaları yer almaktadır. 4. Bölge ise Şeyh Şamil Mahallesi'nin bir bölümünü kapsamakta olup yüksek katlı konut bloklarından oluşmaktadır. Konut binaları ağırlıklı olarak zemin dahil 15 kata sahiptir. Bu bölge son 10 yılda çok hızlı kentleşmiştir. Analizlerin yapılması amacıyla, belirlenen bu çalışma alanlarının bilgisayar ortamında üç boyutlu katı modelleri hazırlanmıştır. 1. aşamada bu modeller üzerinden Townscope III yazılımı ile SVF (gökyüzü açıklığı) değerleri hesaplanmış ve bölgelere ait SVF haritaları elde edilmiştir. Tüm bölgelerde SVF hesapları yer seviyesinden $150 \mathrm{~cm}$ yüksekliğinde gerçekleştirilmiştir. Bölgelerde 3 metre sıklıkla oluşturulan gridal ağ dikkate alınarak hesapların gerçekleştirileceği noktalar belirlenmiştir. Binaların içerisinde kalan noktaların tümü kaldırılmıştır. Hesaplanan SVF değerleri yüzde (\%) olarak gösterilmiştir. 2. aşamada ise elde edilen gökyüzü açıklık değerlerine bağlı olarak Oke'nin [8] formülü ile yaklaşık olarak maksimum kentsel 1sı adası şiddetinin değerleri hesaplanmıştır.

\section{SEÇILEN BÖLGELERDE ELDE EDÍLEN BULGULAR}

Değerlendirme için seçilen bölgelerin dış sınırları belirlenirken, yakın çevrelerinde büyük boş alanların yer almamasına dikkat edilmiştir. Bu bölgelerin olabildiğince binalarla sınırlanmış 
olmaları önemli görülmüştür. Sınır belirlemede gösterilen bu hassasiyetle, içe dönük kentsel dokulardan daha anlamlı sonuçların elde edileceği düşünülmüştür. Seçilen bölgelerin iç kısımlarında geniş yaya dolaşım alanları (park veya kentsel dış mekan) yer almıştır. Tamamen binalardan oluşan bir doku olmayıp onlarla birlikte kentsel boşluklar da değerlendirmeye alınmıștır. Böylece sınır tanımlamada yer alan çok sayıda seçenek içerisinde, temsil değeri yüksek ve doluş/boş anlamında dengeli kent dokuları belirlenmeye Çalışılmıştır. $\mathrm{Bu}$ yaklaşımla bölgelere ait SVF ortalamalarında tutarlı değerlerin elde edilmesi hedeflenmiştir.

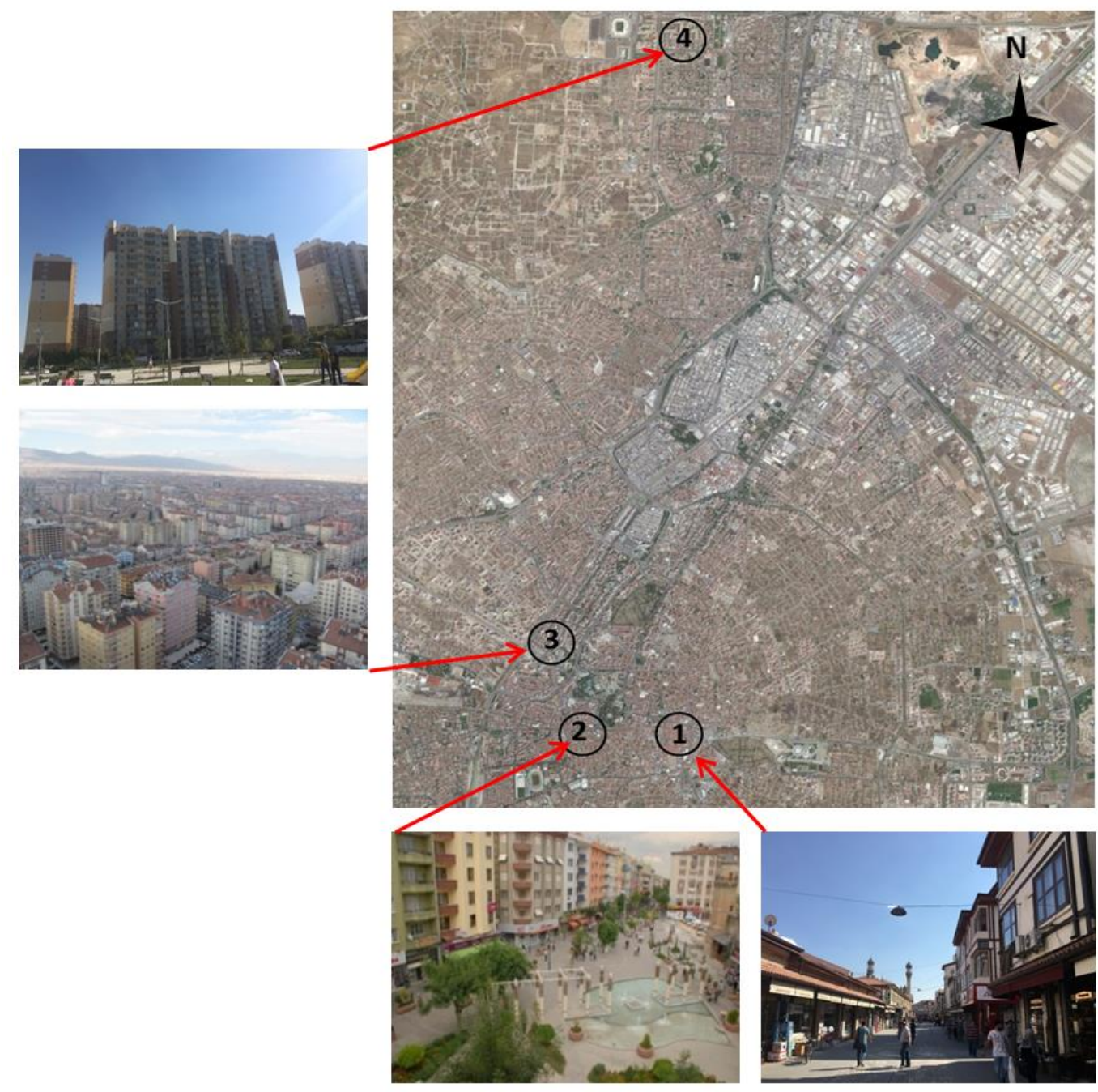

Şekil 3. Seçilen bölgelerin Konya kentinde konumları

4.1. Bölgelerde Gerçekleşen SVF, $\Delta T_{u-r(\max )}$ Hesaplamaları ve Değerlendirmeler

Öncelikle seçilen kentsel dokular içerisinde genel SVF ortalamaları hesaplanmıştır. Bölgelerde SVF dağılımlarındaki çeşitliliği gösterebilmek için çok kapalıdan çok açığa doğru alan gökyüzü açıklık değerleri 5 farklı grupta yüzde olarak gösterilmiștir. Yüzde dağllım içerisindeki gruplandırma 20 puan arayla yapılmıştır. 
Genelde seçilen kentsel dokularda tam anlamıyla homojen bina yükseklikleri bulunmamaktadır. Bina aralıkları ve yol genişlikleri de farklı ölçülerdedir. Kentsel diş mekanların geometrisi ve boyutları da çeşitlilik göstermiştir. Bütün bunlar dolu boş dağılımlarını çok yönlü etkilemiş dolayısıyla farklı SVF değerleri ortaya çıkmıştır. Çizelge 1'de bölgelerdeki noktalara ait SVF dağılımlarının yüzdesi yer almaktadır. Çizelge 2'de ise bölgelere göre ortalama, minimum, maksimum SVF ve maksimum 1S1 adas1 $\left(\Delta \mathrm{T}_{\mathrm{u}-\mathrm{r}(\max )}\right)$ değerleri görülmektedir.

Çizelge 1. Seçilen bölgeler için hesaplanan nokta sayısı ve SVF dağılımları

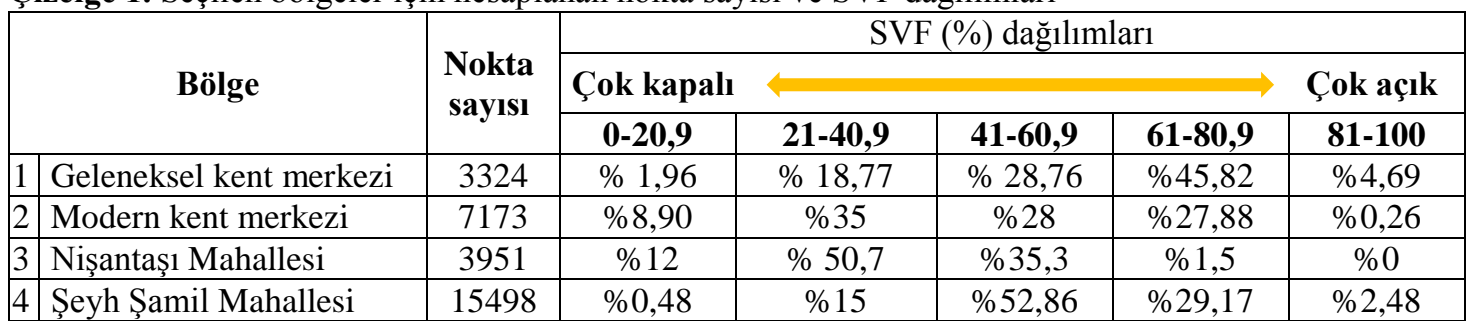

Çizelge 2. Seçilen bölgeler için ortalama, minimum ve maksimum SVF ve $\Delta \mathrm{T}_{\mathrm{u}-\mathrm{r}(\max )}$ değerleri

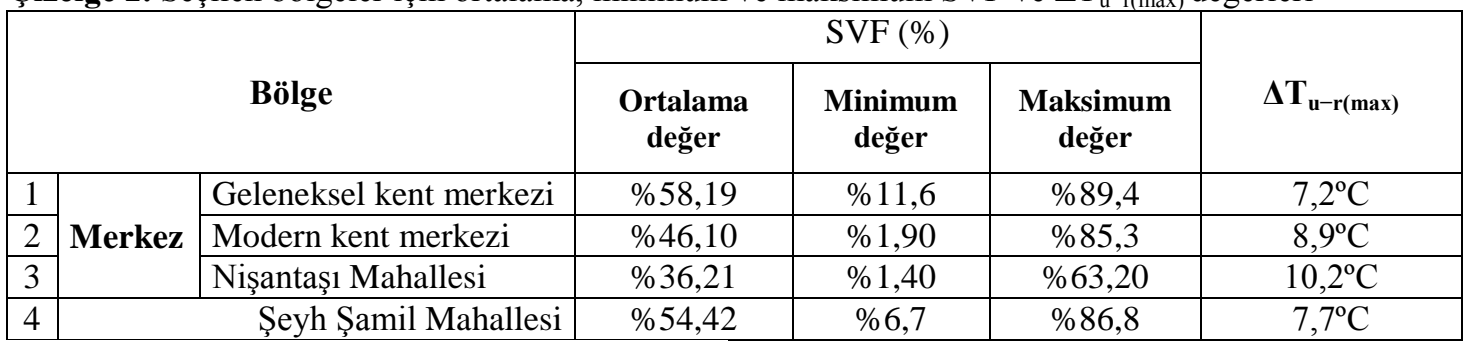

Geleneksel kent merkezinin (1. bölge) ortalama SVF değeri \%58,19 olup bölgeler içerisinde en yüksek olanıdır (Şekil 4). Orta derece ile açık arası bir SVF değerinden söz edilmesi mümkündür. Bölgedeki noktaların yaklaşık yarısı açık ve çok açık olarak nitelenebilecek SVF değerlerine sahiptir. Çok açık olarak nitelenebilecek noktaların genel dağılımdaki oranı \%4,69'tur. Bu bölgedeki SVF dağılımlara bakıldığında minimum değer \%11,6 maksimum değer ise \%89,4'tür.

Günümüzün modern kent merkezinin (2. bölge) ortalama SVF değeri \%46,10 olup açıklık derecesi orta düzeye yakın kabul edilebilir (Şekil 4). Kapalı kabul edilebilecek noktaların SVF değerleri \%21-\%40,9 aralı̆̆ında olup \%35 oranında bulunmaktadır. Noktaların \%8,90’u çok kapalı olarak nitelenebilecek SVF değerlerine sahiptir. Bu noktalar geniş diş mekanların ve boşlukların olmadığı, dar sokakların yer aldığ alanlarda sıklaşmaktadır. Açık olarak nitelenebilecek SVF değerlerine sahip noktalar \%27,88 oranında yer almaktadır. Bu noktalar yaya dolaşım alanlarında ve açık kentsel alanlarda artmıştır. Açık gökyüzü koşullarına sahip noktaların sayısı düşük olup bulunma oranı \%0,26'dır. Bu bölgedeki minimum SVF değeri \%1,90, maksimum değeri ise \% 85,3'tür.

Nişantaş1 mahallesinde (3. bölge) ortalama SVF değeri belirlenen bölgeler arasında en düşük olanıdır (Şekil 4). Ortalama SVF değeri \%36,21'dir. Yüksek yapılaşmaya sahip bölgede noktaların SVF dağılımları sırayla şu şekildedir: \%50,7 oranında kapalı, \%12 oranında çok kapalı ve \%35,3 oranında orta düzeyde kapalı. Çok açık gökyüzü koşullarına sahip nokta bulunmamaktadır. Minimum SVF değeri $\% 1,40$ maksimum değeri ise \% 63,20'dir. Yüksek katl1 binalar ve yap1 adası içerisinde binalar arası mesafelerin oldukça yakın olması bölgedeki SVF değerlerinin çoğunlukla düşük çıkmasına neden olmuştur. 

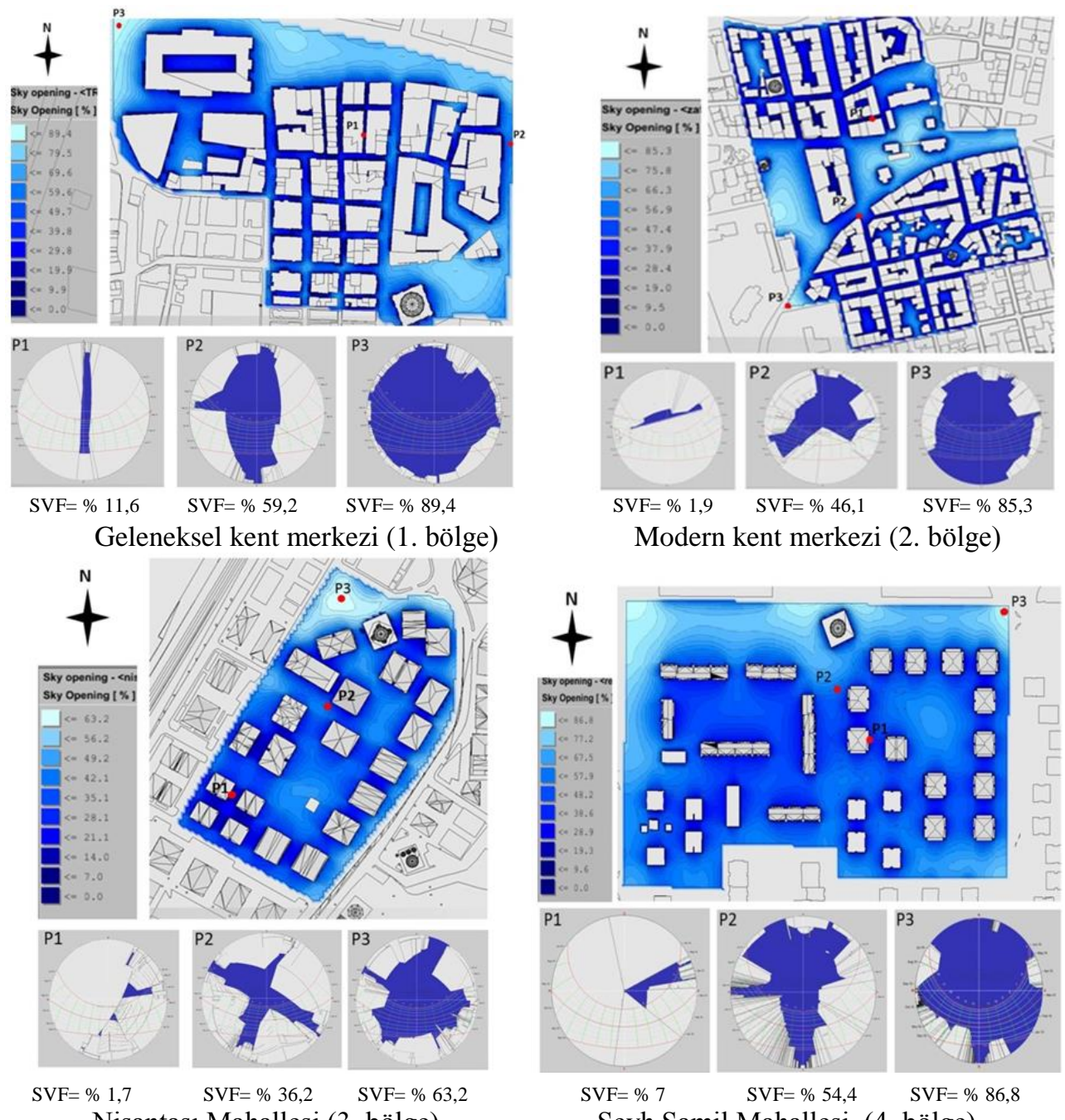

Nişantaşı Mahallesi (3. bölge)

Şeyh Şamil Mahallesi (4. bölge)

Şekil 4. Bölgelere ait SVF dağılım haritası ve her bölgede 3 noktanın SVF değerleri

Kent merkezinin dişında kalan ve yeni kentleşen alanları temsil değerinde olan Şeyh Şamil mahallesinde (4. bölge) ortalama SVF değeri $\% 54,42$ 'dir. Bu mahalle orta düzeyde bir kapalılık derecesine sahiptir (Şekil 4). Genel SVF dağılımlarına bakılırsa; noktaların \%29,17 açık, $\% 2,48$ ise çok açık gökyüzü koşullarına sahip olduğunu söylemek mümkündür. Noktaların \%15'i Kapalı gökyüzü koşullarına sahiptir. Bölgenin minimum SVF değeri \%6,7, maksimum değeri ise $\% 86,8$ 'dir. Yüksek katlı bir yapılaşmaya rağmen, var olan ortak kullanımlı geniş dış mekânlar, SVF değerlerinin çok düşük çıkmasını engellemiştir. $\mathrm{Bu}$ bölgede var olan kapalı sitelerde, sosyal kullanım amaçlı kamusal alanlar önemli kentsel boşluklar oluşturmaktadır. Genelde kentte yeni planlanan bölgelerde bu tasarım yaklaşımı dikkat çekmektedir. Yüksek katlı binaların olduğu bölgelerde bu kamusal mekânların SVF değerlerini arttırma yönünde etki yaptığını söyleyebiliriz.

Çizelge 2'de ortalama SVF değerlerine göre bölgelerde oluşabilecek maksimum kentsel 1s1 adası etkisinin yaklaşık değerleri yer almaktadır. 
Elde edilen sıcaklık değerleri yoğunluk ile ters orantılı çıkmıştır. Sonuçlar dikkate alındığında, yüksek yoğunluktaki yapılaşmadan dolayı, en yüksek 1sı adası etkisi Nişantaşı mahallesinde görülmektedir $\left(10,2{ }^{\circ} \mathrm{C}\right)$. Ardından kent merkezi $\left(8,9{ }^{\circ} \mathrm{C}\right)$, Şeyh şamil mahallesi $\left(7,7{ }^{\circ} \mathrm{C}\right)$ ve geleneksel kent merkezi $\left(7,2^{\circ} \mathrm{C}\right)$ gelmektedir.

\subsection{Tartışma}

Elde edilen sonuçlar dikkate alındığında, maksimum 1sı adası etkisinin, yoğun yapılaşmaya sahip kentsel alanlarda oluşma ihtimalinin daha yüksek olduğu görülmektedir. Kentin geometrik yapısının dikkate alınmasıyla elde edilen bu sonuçlar bir ön tahmindir ve planlama/tasarım disiplinleriyle uğraşanlara ilk fikirleri vermesi bakımından önemlidir. Ancak bu sonuçların çok yönlü olarak değerlendirilmesi daha sağlıklı bir bakış açısı kazandıracaktır. Kentsel 1sı adası etkisi, çok sayıda kontrol edilebilir ve edilemeyen değişkenlere bağlı olarak meydana geldiği için çok net olarak belirlenmesi güçtür. Bu gerçek dikkate alınarak Konya kentinin içinde bulunduğu karasal iklim koşulları ve gece gündüz zaman aralıkları dikkate alınarak yorumların yapılması uygun olacaktır.

Yaz dönemlerinde 1sı adası etkisini azaltmak için, az yoğun yerleşim alanlarının (yüksek SVF değerleri) planlanması doğru bir yaklaşım olarak kabul edilebilir. Yoğun dokuların (düşük değerde SVF) yaz dönemlerinde gündüz saatlerinde gölge oluşturmaları avantajlı bir durum olarak görülebilir. Ancak Konya iklim koşullarında binaların güneşe erişimleri kış dönemlerinde önemsenmesi gerekmektedir. Yoğun yapılaşma, kış günlerinde binaların güneşten yararlanma durumunu azaltacağı bir gerçektir. Kent ortamının gökyüzü açıklık düzeyi bütünsel bir yaklaşımla ele alınması gerekmektedir. Bu durumda Konya iklim koşullarında SVF değerlerinin yüksek olması, yani açık gökyüzü koşullarının desteklenmesi daha avantajlı görülmektedir. Böylece yaz dönemlerinde gece oluşan 1S1 adası etkisinin azaltılması ve kışın da az yoğun yapılaşmaya bağlı olarak binaların güneşten pasif anlamda yararlanabilmeleri mümkün olabilecektir. Bu kabul doğrultusunda, yaz günlerinde gündüz saatlerinde güneşlenmenin olumsuz koşullarından korunmak için özellikle mimari ölçekte çözümler gerçekleştirilmesi gerekmektedir. $\mathrm{Bu}$ önlemler dizisi, hem bina iç kullanıcılarının hem de kent ortamında özellikle kamusal alanlarda dış mekan kullanıcılarının termal konfor koşullarının iyileştirilmesiyle ilgili olmalıdır. Kentsel ortamda mimari çözümlerle ve ağaçlandırma gibi bitkisel unsurlarla gölgeli mekânların var edilmesi gerekmektedir. Mimari bir çözüm olarak yeşil cephe ve çatı uygulamaları desteklenebilir ve yaygınlaştırılabilir. Ancak sözü edilen bu önlemler dizi, kentin geometrik yapısını kalıcı olarak belirleyen bina yükseklikleri, aralıkları ve biçimleri gibi temel fiziki değişkenlerle beraber tamamlayıcı özellikte olabilirler.

\section{SONUÇ}

Günümüzde global ölçekte önemli yer tutan iklimsel değişim ve artan kentleşme olguları dikkate alındığında, kentsel iklim araştırmalarının önemi ortaya çıkmaktadır. Kentlerimizde yer yer var olan yüksek yoğunluklu yapılaşma anlayışı, beraberinde olumsuz mikroklimatik koşulların oluşmasına yol açacağı açıktır.

Çalışmada kentlerin geometrik yapısının neden olabileceği 1S1 adas1 etkisinin belirlenmesinde SVF yani gökyüzü açıklık değerleri dikkate alınmıştır. SVF kentteki yapısal yoğunluğun değerlendirilmesinde başvurulabilecek bir parametredir. Çalışma alanı olarak belirlenen Konya kenti bağlamında seçilen 4 bölgede, gökyüzü açıklık değerleri dikkate alınarak oluşabilecek maksimum kentsel 1s1 adası etkileri yaklaşık olarak hesaplanmıştır. Oluşması muhtemel 1s1 adası etkisinin şiddeti, yüksek yoğunluklu yapılaşmaya sahip alanlarda daha yüksek görülmektedir.

Kentleşme aktivitelerin devam ettiği ülkemizde, planlama ve tasarım aşamalarında yapılaşma yoğunlukları belirlenirken SVF parametresi bir girdi olarak değerlendirilebilir. Bilinen yoğunluk değerleri, yapılı çevrenin toprakla olan ilişkisini ortaya koyarken, SVF parametresi farklı olarak yapılı çevrenin gökyüzü ile olan ilişsisini 
belirlemektedir. Bu yaklaşım sayesinde atmosferle, gökyüzü ile olan ilişki düzeyi belirlenebilmektedir. Dolayısıyla bu parametre ile is1 adası etkisinin belirlenmesi önceden mümkün olabilmektedir. Şehir plancıları genel planlama yaklaşımlarında, mimarlar da ada bazında gerçekleştirecekleri düzenlemelerde, mikroklimatik sonuçların bir ön tahminini yapabilmeleri önemlidir. Planlama ve tasarım aşamasında yapılı çevrenin geometrik yapısı kesin bir şekilde belirlendiği için, bu aşamada şehir plancıları ve mimarların bilinçli kararlar almaları gerekmektedir.

Mimarlar yoğun kentsel dokularda 1S1 adas1 etkisini azaltabilmek için tasarım aşamasında, bina yüzeylerini oluşturan malzemelerin yansıtma katsayılarını daha yüksek değerde seçebilirler. Dış mekân düzenlemelerinde yeşil dokunun yoğunluğunu arttırarak evapotranspirasyonla soğutmanın gerçekleşmesini sağlayabilirler.

Kentsel planlamada, kentlerin oluşumunda önemli bir gösterge olan yoğun değerlerinin çok yönlü etkileri dikkate alınmalıdır. Nüfus, ulaşım, yeşil doku ve bina tipolojisi gibi girdilerin yanında mikroklimatik sonuçlar da düşünülmelidir. Yeryüzünün içinde bulunduğu olumsuz çevresel koşulların azaltılması için kent ölçeğinde mikroklimanın iyileştirilmesi önemli bir planlama ve tasarım stratejisi olarak ele alınmalıdır. Kentlerin oluşumunda önemli rolleri olan kentsel planlama ve mimari tasarım disiplinlerinde, tasarım ölçekleri arasında koordineli çalışmalar yapılmalı, her ölçekte mikroklimayı iyileştirecek tasarım önlemleri alınmalıdır.

\section{TEŞEKKÜR}

Çalışmada Townscope yazılımı kullanımı konusunda destekleri için Liège Üniversitesi (Belçika) Lema Araştırma Merkezi Müdürü Prof. Dr. Jacques Teller'e teşekkürlerimi sunmak isterim.

\section{KAYNAKLAR}

1. Nakata C., Souza L., 2013. Verification of the Influence of Urban Geometry on the Nocturnal
Heat Island Intensit, Journal of Urban and Environmental Engineering, 7(2), 286-292.

2. Allegrini, J., Dorer, V., Carmeliet, J., 2015. Influence of Morphologies on the Microclimate in Urban Neighbourhoods. Journal of Wind Engineering and Industrial Aerodynamics, 144, 108-117.

3. Mirzaei, P.A., Haghighat, F., 2010. Approaches to Study Urban Heat IslandAbilities and Limitations. Building and Environment, 45 (10), 2192-2201.

4. Chung, M.H., Park, J.C., 2016. Development of PCM Cool Roof System to Control Urban Heat Island Considering Temperate Climatic Conditions. Energy and Buildings, 116, 341-348.

5. Rzepa, M., 2009. The Map of Sky View Factor in the Center of Lodz, The Seventh International Conference on Urban Climate, Yokohama.

6. Guo, G., Zhou, X., Wu, Z., Xiao, R., Chen, Y., 2016. Characterizing the Impact of Urban Morphology Heterogeneity on Land Surface Temperature in Guangzhou, China, Environmental Modelling and Software, 84, 427-439.

7. Cheung, H.K.W., Coles, D., Levermore, G.J., 2016. Urban Heat Island Analysis of Greater Manchester Uk Using Sky View Factor Analysis, Building Services Engineering Research and Technology, 37, 5-17.

8. Oke, T.R., 1981. Canyon Geometry and the Nocturnal Urban Heat Island: Comparison of Scale Model and Field Observations. Journal of Climatology, 1(3), 237-254.

9. White, M., Kimm, G., 2015. Measuring Sky View Factor of Urban Canyons Using Hacked Gopro Hemispheric Video Processing, Living and Learning: Research for a Better Built Environment: $49^{\text {th }}$ International Conference of the Architectural Science Association, Melbourne.

10. Athamena, K., 2012. Modelling and Simulation of Urban Microclimates : Study of the Impact of Urban Morphology on Comfort in Outside Spaces, Cases of Eco-Districts, Doctorate Thesis, Ecole Centrale de Nantes (ECN).

11. Steemers, K.A., Ramos, M.C., Sinou, M., 2004. Urban Morphology, Rediscovering the 
Urban Realm and Open Spaces, Designing Open Space in the Urban Environment: A Bioclimatic Approach M. Nikolopoulou, Editor, Centre for Renewable Energy Sources, CRES, Department of Buildings, Greece, 20-25.

12. Rizwan, A.M., Dennis, L.Y.C., Liu, C., 2008. A Review on the Generation, Determination and Mitigation of Urban Heat Island, Journal of Environmental Sciences, 20(1), 120-128.

13. Göksu, Ç., 1999. Güneş Kent, 2 ed., Göksu Yayınları, Ankara.

14. Chen, L., Ng, E., An, X., Ren, C., Lee, M., Wang, U., He, Z, 2012. Sky View Factor Analysis of Street Canyons and its Implications for Daytime Intra-Urban Air Temperature Differentials in High-Rise, High-Density Urban Areas of Hong Kong: A GIS-Based Simulation Approach, International Journal of Climatology, 32(1), 121-136.

15. Paramita, B., Fukuda, H., 2014. Heat Intensity of Urban Built Environment in Hot Humid Climate Region. American Journal of Environmental Sciences, 10(3), 210-218.

16. Bouyer, J., 2009. Modelling and Simulation of Urban Microclimates-Study of the Urban Planning Impact on the Buildings Energy Consumption, Doctorate Thesis, Université de Nantes.

17. Theophilou, M.K., Serghides, D., 2015. Estimating the Characteristics of the Urban Heat Island Effect in Nicosia, Cyprus, Using Multiyear Urban and Rural Climatic Data and Analysis, Energy and Buildings, 108, 137-144.

18. Tsoka, S., 2011. Relations Entre Morphologie Urbaine, Microclimate et Confort des Piétons: Application au Cas des Ecoquartiers, Master Thesis, Centre Scientifique et Technique du Bâtiment [CSTB], Nantes.

19. Mathew, A., S. Khandelwal, S., Kaul, N., 2016. Spatial and Temporal Variations of Urban Heat Island Effect and the Effect of Percentage Impervious Surface Area and Elevation on Land Surface Temperature: Study of Chandigarh City, India. Sustainable Cities and Society, 26, 264-277.

20. Ward, K., Lauf, S., Kleinschmit, B., Endlicher, W., 2016. Heat Waves and Urban Heat Islands in Europe: A Review of Relevant Drivers.
Science of the Total Environment, 569-570, 527-539.

21. Gál, T., Lindberg, F., Unger, J., 2008. Computing Continuous Sky View Factors Using 3D Urban Raster and Vector Databases: Comparison and Application to Urban Climate. Theoretical and Applied Climatology, 95(1-2), 111-123.

22. Unger, J., 2009. Connection Between Urban Heat Island and Sky View Factor Approximated by a Software Tool on a 3D Urban Database, International Journal of Environment and Pollution, 36 (1-3), 59-80.

23. Debbage, N., 2013. Sky-View Factor Estimation: A Case Study of Athens, Georgia. Geographical Bulletin-Gamma Theta Upsilon, 54(1), 49-57.

24.Zhu, S., Guan, H., Bennet, J., Clay, R., Ewenz, C., Benger, S., Maghrab, A., Millington, A.C., 2013. Influence of Sky Temperature Distribution on Sky View Factor and its Applications in Urban Heat Island. International Journal Of Climatology, 33(7), 1837-1843.

25. Li, W., Putra, S.Y., Yang, P.P.J., 2004. GIS Analysis for the Climatic Evaluation of 3D Urban Geometry. The Development of GIS Analytical Tools for Sky View Factor, GISDECO: Roceedings of the $7^{\text {th }}$ International Conference on GIS for Developing Countries, Johor, Malaysia.

26. Liao, J.W.L., Cavaleri, M.M., 2014. The Study of Sky View Factor, Urban Morphologies: Computational Tools and Methods of Analysis, $30^{\text {th }}$ International PLEA Conference Sustainable Habitat for Developing SocietiesChoosing the Way Forward, Ahmedabad, India, Cept University Press Centre for Documentation \& Publications.

27. Kakon, A.N., Nobuo, M., 2009. The Sky View Factor Effect on The Microclimate of a City Environment: A Case Study of Dhaka City, The Seventh International Conference on Urban Climate, Yokohama Japan, 29 June-3 July.

28. Krüger, E.L., Bröde, P., 2013. Analyzing the Relationship between Local Urban Morphology and Predicted Thermal Perception, 29 ${ }^{\text {th }}$ PLEA 2013 Conference, 
Sustainable Architecture for a Renewable Future, Munich, Germany.

29. Yuan, C., Chen, L., 2011. Mitigating Urban Heat Island Effects in High-Density Cities Based on Sky View Factor and Urban Morphological Understanding: A Study of Hong Kong. Architectural Science Review, 54(4), 305-315.

30. Rafiee, A., Dias, E., Koomen, E., 2016. Local Impact of Tree Volume on Nocturnal Urban Heat Island: A Case Study in Amsterdam. Urban Forestry \& Urban Greening, 16, 50-61.

31. Hu, Y., White, M., Ding, W., 2016. An Urban Form Experiment on Urban Heat Island Effect in High Density Area, Procedia Engineering.

32. Wu, X., Liu, N., 2014. Study of the Relationship between Sky View Factor and Urban Plaza Conformation, New Urban Configurations, 574-582.

33. Svensson, M.K., 2004. Sky View Factor Analysis, Implications for Urban Air Temperature Differences, Meteorological Applications, 11(3), 201-211.

34. Wenjing, L., 2005. Using Sky View Factor As an Indicator for GIS-Based Analysis of 3D Urban Geometry in Relation to Thermal Performance, Master Thesis, Department of Architecture School of Design and Environment, National University of Singapore.

35.Li, W., Putra, S.Y., Yang, P.P.J., 2004. Climatic Performance of 3D Urban Geometry: GIS-Based Analyses on Sky View Factor Patterns, IUPEA6, Louisville.

36. Oke, T.R., 1987. Boundary Layer Climates. second ed., Routledge Taylor \& Francis Group.

37. Montávez, J.P., González-Rouco, J.F., Valero, F., 2008. A Simple Model for Estimating the Maximum Intensity of Nocturnal Urban Heat Island. International Journal of Climatology, 28(2), 235-242.

Yazılım: Townscope III 